\title{
Impact of Impairment on Children with Special Needs at School Entry: Comparison of School Readiness Outcomes in Canada, Australia, and Mexico
}

\author{
Magdalena Janus \\ McMaster University
}

\begin{abstract}
Transition to school is particularly complex for children with special needs. A major difficulty faced by educational systems in trying to address these needs is the multitude of problems with which such children present. Based on populationlevel data collected with the Early Development Instrument in Canada, Australia, and Mexico, kindergarten-level school readiness outcomes in relation to particular impairments are explored here. Learning and behaviour problems have an overall impact on children's school readiness, while physical, hearing, and vision impairments appear to affect only the area directly related to the impairment. Overall, the results show some variation but also remarkable similarities among the countries.
\end{abstract}

The early years are critical for setting children on a trajectory of success, since the shape of an education trajectory is often established early in a child's school career (Entwisle \& Alexander, 1999; Jimerson, Egeland, \& Teo, 1999; Ramey \& Ramey, 2004). In order to develop optimally in this context, and be well prepared for later educational attainment and adult health, a child needs to be ready and able to profit from the social and academic environment provided by the school (Janus \& Offord, 2007; Zuckerman \& Halfon, 2003). According to Meisels (1999), readiness is a process which develops over the preschool years, is influenced by the school context, and is an outcome of the child's progress to date. School readiness includes both cognitive and non-cognitive factors, hard and soft skills, general knowledge and approaches to learning, and academic and socio-emotional components (Forget-Dubois et al., 2007; Janus \& Duku, 2007). Preschool children who need special assistance due to an already diagnosed disabling mental or physical condition — often called "special needs"-face a complex transition to school. This is an issue of much anxiety for parents and of concern to service providers (Janus, Kopechanski, Cameron, \& Hughes, 2008).

One of the main barriers in effective programming for children with special needs is the heterogeneity of the problems with which they present (Fowler, Schwartz, \& Atwater, 1991). 
Due to small numbers of children with any given diagnosis in any given year, educational systems cannot respond with interventions tailored to specific conditions. Clearly, the facilitation of the transition process, as well as accommodations and adjustments should be based on a child's functional status. Currently, however, more often than not the accommodations made for children with special educational needs are based on availability of resources (Duncan, 2003; Janus, et al., 2008). Delay related to the administrative process is often yet another barrier. Funding and programming is based on an assessment of children's skills once they enter school, rather than on the information gathered prior to entry, which would enable the educational systems to promptly address these needs (Valeo, 2003; Wolery, 1999).

The research evidence of effectiveness of practices applied to facilitate the process of transition to school for children with special needs is much needed yet not widely available (McIntyre \& Wildenger, 2011). Previous research and several reviews (i.e., Early, 2004; Janus, Lefort, Cameron, \& Kopechanski, 2007; McIntyre \& Wildenger, 2011; Wolery, 1999) indicate that communication between programs or agencies and individuals involved with children at the two ends of the transition process is uneven and difficult, leading to calls for establishing dedicated policies or even committees (Conn-Powers, Ross-Allen, \& Holborn, 1990; Fowler et al., 1991; Pianta \& Kraft-Sayre, 2003; Rous, Hemmeter, \& Schuster, 1994). Moreover, teachers with disability-related training or experience tend to have a positive attitude towards inclusive education (Mulvihill, Shearer, \& Lee Van Horn, 2002).

Lack of reliable information on the specific areas of impairment that influence the kindergarten and future outcomes of children with special needs is likely impeding the assessment of the effectiveness of transition practices. While most of transition to kindergarten practices are implemented locally at school level (e.g., Early, Pianta, Taylor, \& Cox, 2001; LoCasale-Crouch, Mashburn, Downer, \& Pianta, 2008), they need to reflect policies that are made at higher jurisdictional levels, those of a district, or a state or province (Janus, 2004). Services for young children with disabilities in transition to school are often fragmented and uncoordinated, and based on availability rather than evaluation of effectiveness. Evidence linking children's functional impairment with kindergarten outcomes could be helpful in providing direction to policy in strategies for transition planning.

Few countries, if any, have comprehensive community-based information on the school readiness outcomes for children with special needs. The assessment procedures used with children with special educational needs often take time, sometimes up to a year, to establish the individual education plan. Clearly, this population requires an individualized approach; nevertheless, the overall, function-focused information on the status of school readiness among children with diverse impairments is crucial for a broadly-based approach, which addresses these needs before children enter school.

An opportunity to explore the kindergarten-level outcomes for children with a variety of special needs based on population-level data comes from the wide use of the Early Development Instrument (EDI, Janus \& Offord, 2007). The EDI is a teacher-completed checklist, containing just over 100 core items grouped into five developmental domains. The EDI captures the status of children's early development prior to entry to grade school. Since it has been conceived to provide communities with child development information that could be related to local contextual factors, the EDI is implemented for all kindergarten children in a geographical area. The population-based database allows for analyses of data for small and low-frequency groups such as children with special educational needs. The existing EDI databases of children in Canada, Australia, and Mexico offer unparalleled advantage of exploring empirical levels of 
children's readiness to learn at school for several reasons. First, the instrument covers the relevant developmental areas. Second, due to its implementation for whole populations of children, databases include data for all children in the community, and not only a sample of them. Third, on account of such wide-scale implementation, it allows aggregation of information for populations of children with specific characteristics who otherwise may contribute only very few scores to community-level data. In the majority of communities, subgroups of children with special needs often constitute less than $5 \%$ of the whole kindergarten population. In this paper, we explore the EDI outcomes for children with special needs diagnosed prior to school entry in Canada, Australia, and Mexico.

In Canada, school education is under provincial jurisdiction. The provincial Ministries of Education throughout the country have established policies and protocols addressing needs of individual children (e.g., Janus et al., 2007). All 13 provinces and territories claim to support a policy of inclusion in administering special needs education, and most provide specific definitions of impairments. In 11 of those, the provincial/territorial Ministries of Education focus on procedures regarding the development of a modified curriculum or education plan based on a student's needs. Only 4 of the 13 provinces and territories have a model or protocol, which lays out a detailed identification and planning process for facilitating the learning of children with special needs and links this planning to the school entry process. Only one province (Manitoba) has a fully developed protocol which outlines a list of suggested participants along with their corresponding roles and responsibilities, a comprehensive needs inventory, authorization forms for the exchange of information, and an action plan checklist (Healthy Child Manitoba, 2002). The patchwork of support services and pools of funding connected to this claim demonstrates that the experience of transitioning from the pre-school to elementary school environment varies drastically between jurisdictions.

Similar jurisdictional division exists in Australia and Mexico. Since the introduction of the Commonwealth Disability Discrimination Act in Australia in 1992, a school could not deny admission to children with special educational needs (Dempsey, Foreman, \& Jenkinson, 2002), which prompted increased inclusion of these children in regular classrooms. While the law was introduced at the federal level, the educational policies of individual states and territories are the main determinants of specific provision of educational services for students with special needs. Each state has its own list of specific impairments with definitions and categories and a process for classification (Aussie Educator, n.d.). Despite differences, most jurisdictions offer similar assessment and integration strategies. For example, Australian Capital Territory (2004) distinguished eight categories: intellectual disability, language disorder, physical disability, hearing, vision, pervasive developmental disorder, mental health disorder, and chronic medical condition. In Victoria, the Department of Education and Early Childhood Development is providing an enhanced transition support for children with severe disabilities to facilitate inclusion and children's adjustment to school (Victoria Department of Education and Early Childhood Development, n.d.). Like in Canada, there is no uniform policy to facilitate the transition to school for children with special needs.

The governance of educational policy in Mexico, while also decentralized since the early 1990s, is controlled centrally to a greater degree than in either Canada or Australia, with a federal education body that still appears to have the major decision-making powers (Santibañez, Vernez, \& Razquin, 2005). Nevertheless, the administration of educational policies and educational institutions fall under the state jurisdictions. Inclusive education for children with disabilities was established by a law in 1993, which also guaranteed that states would serve peo- 
ple with special needs (Mount-Cors, 2007). According to the educational policies developed from this law, students with special needs have the right to additional resources to learn the national curriculum content. In assessing children's needs, educators are encouraged to use a holistic approach, including the contextual factors like school, home, and community, as well as teaching methods and the child's particular problems. The special education assessment includes only five broad categories: auditory, motor, intellectual, visual, and other.

In this paper, accessing data for three countries collected with the EDI at a population level, we report on the subpopulation of children with special needs. First, their outcomes are compared with those of the general population of children without special needs. These analyses are followed by an attempt to establish whether there are any specific impairments - among those included on the EDI - that are of particular risk for either of the subpopulations (with and without special needs). Finally, the subgroup of children without identified special needs, but who are judged by teachers to require further assessment, is investigated to establish the extent to which they exhibit problems that may influence their ability to transition to Grade 1 . All these analyses are presented for Canada, Australia, and Mexico in order to establish whether the patterns are idiosyncratic or universal.

The following research questions are addressed: (a) What is the magnitude of difference in school readiness before Grade 1 between children with special needs and typically-developing children? (b) To what extent do the children judged as needing further assessment exhibit difficulties in comparison with children with and without special needs? (c) Are there systematic differences in school readiness with respect to specific impairments within each of the groups? and (d) Are the patterns investigated above similar across the three countries?

\section{Method}

\section{Measure}

The Early Development Instrument. The Early Development Instrument (EDI) is a teacher-completed 104-question checklist measuring children's readiness to learn at school before entry to Grade 1 in five domains. The psychometric properties as well as evidence on the construct and concurrent validity of the EDI are described in detail in the paper reporting on the development of the EDI (Janus \& Offord, 2007). There have been a number of further investigations and reports on various aspects of validity of the EDI, including international comparisons (e.g., Andrich \& Styles, 2004; Forget-Dubois et al., 2007; Guhn, Gadermann, \& Zumbo, 2007; Guhn \& Goelman, 2011; Janus, Brinkman, \& Duku, 2011; Janus, Duku, \& Hughes, 2010; Janus et al., 2007). For example, Forget-Dubois et al. (2007) explored the EDI's predictive validity over a 1-year period and demonstrated that kindergarten EDI scores shared as much variance with children's achievement in Grade 1 as direct cognitive assessment. The use of differential item functioning analyses on Canadian EDI data for 40,000 children indicated no item-level bias on the EDI in relation to children's gender or Aboriginal status (Guhn et al., 2007). EDI results for children with different types of special needs in Canadian normative data are described by Janus et al. (2010). Linkage with Grade 4 outcomes for children with special needs is reported by Lloyd, Irwin, and Hertzman (2009). Internationally, EDI's validity and comparisons among countries were also reported (i.e., Brinkman et al., 2007; Janus, 2011; Janus et al., 2011).

The Physical Health and Well-being domain refers to children's physical preparedness for the school day, fine and gross motor skills, energy level throughout the day, and physical 
independence. The Social Competence domain covers several areas: competence and cooperation in working together with others, ability to remember and follow rules, curiosity and eagerness, approaches to learning, and problem-solving. The Emotional Maturity domain covers prosocial behaviour, aggression, inattention and hyperactivity, and anxious behaviours. The Language and Cognitive Development domain refers to the child's early literacy (reading, writing, rhyming, recognition of letters and sounds) and covers cognitive aspects of language and numeracy in several areas: basic literacy and numeracy skills, interest and memory, and more complex literacy. The Communication Skills and General Knowledge domain covers the child's ability to clearly communicate one's own needs and thoughts in a way that is understandable both to adults and other children, the ability to understand others, clear articulation, and aspects of general knowledge. In contrast to the previous domain, this one is about effective communication regardless of the grammatical correctness.

In addition to teacher ratings on specific skills grouped into developmental domains, the EDI requests the teachers to report on basic demographic characteristics (age, gender), any specific school board/district special education or special needs classification, and child's first language. Teachers also report whether a child has "special problems that influence his/her ability to do school work in a regular classroom." If the answer is yes, they are requested to mark a box that corresponds to a type of problem the child has (options listed below in Impairments). Corrected impairment (as in the case of vision) is marked only if it influences a child's ability to participate in school activities. As the focus of these categories is on impairment, not diagnosis, if a child has a problem that influences more than one impairment area teachers are expected to mark all areas that apply. At the end of this section, teachers are asked to report whether they feel that the child needs further assessment.

The EDI is completed by teachers in the second half of the kindergarten year, usually over a period of 2-3 weeks. Thus, all children are at the same grade level, but since the age of entry to kindergarten is based on the child's birthday, in any given classroom the variation in age can be as large as one year.

\section{Databases}

In each of the three countries, the EDI data were collected for all kindergarten-level children within the studied areas, either by the author or under the license from the author, and compiled for the purpose of analyses in this paper. In particular, databases were reduced by excluding children (a) missing or out of appropriate range age, (b) missing gender, and (c) missing two or more domains.

The Canadian data are based on the Normative II database, collected over 3 years: 20052007 (Janus \& Duku, 2008). After the exclusion criteria were applied, a total of 183,710 children were available for analyses, representing $95.4 \%$ of the initial sample. Children with identified special needs comprised a group numbering 7089 (3.9\% of the study sample).

The Australian EDI data were collected in approximately the same time period in 54 sites from seven states and territories (AEDI Partnership, 2007). A total of 31,478 children were available for the analyses in this paper ( $99.9 \%$ of the initial sample), including 1,582 children with special needs ( $5 \%$ of the study sample).

The Mexican EDI data were collected in 2008 in all kindergarten classrooms in the Northern state of Nuevo Leon. A total of 168,400 children were available for analyses $(96.8 \%$ of the initial sample), including 1,690 children with special needs ( $1 \%$ of the study sample). 


\section{Definitions}

The following groups of children, all categorised based on the information from the EDI, are considered. Children with special needs identified before school entry (children with special needs or SN group): a group for whom a health/education problem has been identified according to the guidelines of the respective ministry of education prior to school entry. These children are marked as "having special needs" on the first page of the EDI. Children without special needs (non-SN group): children who were not marked as having special needs. Children who need further assessment (NFA group): a subset of children without special needs. Children without identified special needs, but marked by teacher as "needing further assessment." Note that the $\mathrm{SN} /$ non-SN distinction is based on the appropriate education authority classification on the grounds of a medical or psychological assessment. The NFA category is based on teacher perception.

\section{Impairments}

The specific impairments were based on six special problems included in the EDI: physical impairment, visual impairment, hearing impairment, speech impairment, learning disability, and behaviour problem. In Mexico, the categories of "speech impairment" and "learning disability" were replaced by specific diagnoses and therefore had to be excluded from analyses in this paper. Corrected impairment (as in the case of vision) was marked only if it influenced a child's ability to participate in school activities. As the focus of these categories was on impairment, not diagnosis, if a child had a problem that influenced more than one impairment area teachers marked all areas that applied. In responding, teachers could mark as many as apply. Therefore, in order to explore the extent to which specific impairments affect children's school readiness, groups of children experiencing only one of each of the six impairments studied here were identified.

\section{Analyses}

In order to provide a consistent method of group comparison, independent of the sample size, effect sizes for each of the five EDI domains were calculated in the following way: $\frac{\text { mean (attribute) - mean (control) }}{\text { s.d.(control) }}$. Since it is independent of the measurement or sample size,

effect size of a difference between two groups is the best indicator of how meaningful this difference is. It is customary to interpret the effect sizes of 0 to 0.3 as small, 0.3 to 0.8 as moderate, and greater than 0.8 as large (Husted, Cook, Farewell, \& Gladman, 2000). Negative effect sizes mean the comparison group has lower scores than the control group.

Several group comparisons were carried out. First, the magnitude of difference between children with identified special needs and typically-developing children was established by comparing the groups on the five EDI domains. Second, the impact of having one of the six specific functional impairments (i.e., physical, visual, hearing, speech, learning, and behaviour) was explored: among children without special needs and among children with special needs, separately, by comparing the EDI domains between children who had the specific impairment with those who did not. Next, children with special needs were compared with children identified 
by teachers as needing further assessment. Finally, the impact of a specific problem on children's EDI scores was assessed within the NFA group.

\section{Results}

\section{Descriptive Statistics: Gender and Age Differences}

While the ratio of boys to girls in the total population is about 50:50, boys outnumbered girls in the population with special needs: the rate was approximately $70 \%$ boys to $30 \%$ girls (see Table 1), as well as among the children who need further assessment. These proportions were consistent across countries. In Canada, $2.4 \%$ of all girls and $5.2 \%$ of all boys were classified as having SN. In Australia it was 3.3\% girls and 6.7\% boys; in Mexico, $0.7 \%$ girls and $1.3 \%$ boys.

Children with SN were statistically significantly older than typically-developing children in each of the three countries. As can be seen in Table 1, among children without SN, those with NFA were younger than those without in Canada and Australia, Canada $t(157478)=18.075, p<$ .001 , Australia $t(27787)=2.014, p<.05$, but not in Mexico.

\section{Comparison of Children with and without Special Needs}

Children with SN functioned significantly below the typically-developing children in all domains, as shown by consistently and statistically significantly lower means in all five EDI domains (see Table 2). Without exception, these differences were meaningful and of a large magnitude (all effect sizes were greater than 0.8) in all three countries (see Table 3).

\section{Impact of Specific Impairment on the Differences within Groups}

Children without special needs. When the magnitude of differences on the EDI domains was compared in the group of children without identified special needs, but with a specific impairment or without, it became clear that some impairments carry less impact on school readiness than others (see Table 4 for effect sizes). In all three countries, children with visual impairment did not differ from those without it. Children with physical impairment only showed a meaningfully lower mean score in the Physical Health and Well-being domain in all three countries (effect sizes above -0.8), but only small differences in the other domains in Canada and Australia. In Mexico, these children also scored much lower on the Communication Skills and General Knowledge domain (large effect sizes) and somewhat lower on the remaining three domains (effect sizes -0.47 to -0.71). In Canada, the effect sizes of differences for children with hearing impairment were small for all domains with the exception of Communication Skills and

Table 1

Age and Gender Distribution in the Three Countries

\begin{tabular}{|c|c|c|c|c|}
\hline & & $N$ & $\%$ girls & $\begin{array}{l}\text { age in years } \\
\text { (mean } \pm S D)\end{array}$ \\
\hline \multirow[t]{3}{*}{ Special Needs } & Canada & 7,089 & 30.8 & $5.79 \pm 0.40$ \\
\hline & Australia & 1,582 & 32.4 & $6.05 \pm 0.57$ \\
\hline & Mexico & 1,690 & 35.6 & $5.66 \pm 0.72$ \\
\hline \multirow[t]{3}{*}{ No Special Needs All } & Canada & 176,621 & 49.5 & $5.71 \pm 0.32$ \\
\hline & Australia & 29,896 & 50.3 & $5.94 \pm 0.46$ \\
\hline & Mexico & 166,710 & 49.1 & $5.56 \pm 0.67$ \\
\hline
\end{tabular}


No Special Needs, Need Further Assessment

\begin{tabular}{lrrr} 
Canada & 17,788 & 33.1 & $5.67 \pm 0.33$ \\
Australia & 2,801 & 37.7 & $5.90 \pm 0.49$ \\
Mexico & 5,474 & 34.1 & $5.54 \pm 0.67$ \\
\hline
\end{tabular}

Table 2

Mean and Standard Deviation in the Five EDI Domains for Children Depending on Their $S N$ and NFA Status

\begin{tabular}{|c|c|c|c|c|c|c|c|c|}
\hline \multirow[b]{2}{*}{ Domain } & \multicolumn{2}{|c|}{ SN Status } & \multicolumn{2}{|c|}{ No SN, All } & \multicolumn{2}{|c|}{ No SN, No NFA } & \multicolumn{2}{|c|}{ No SN, NFA } \\
\hline & $M$ & $S D$ & $M$ & $S D$ & $M$ & $S D$ & $M$ & $S D$ \\
\hline \multicolumn{9}{|c|}{ Canada } \\
\hline$N$ & \multicolumn{2}{|c|}{7,089} & \multicolumn{2}{|c|}{176,621} & \multicolumn{2}{|c|}{158,833} & \multicolumn{2}{|c|}{17,788} \\
\hline Physical Health \& Well-Being & 6.85 & 2.03 & 8.80 & 1.30 & 8.97 & 1.13 & 7.59 & 1.68 \\
\hline Social Competence & 5.39 & 2.52 & 8.32 & 1.79 & 8.63 & 1.51 & 6.25 & 2.17 \\
\hline Emotional Maturity & 5.93 & 1.94 & 8.04 & 1.50 & 8.27 & 1.30 & 6.48 & 1.82 \\
\hline Language \& Cogn. Development & 5.65 & 2.97 & 8.44 & 1.79 & 8.73 & 1.45 & 6.42 & 2.48 \\
\hline Communication \& Gen. Knowledge & 3.81 & 3.08 & 7.65 & 2.56 & 8.03 & 2.30 & 5.07 & 2.80 \\
\hline \multicolumn{9}{|c|}{ Australia } \\
\hline$N$ & \multicolumn{2}{|c|}{1,582} & \multicolumn{2}{|c|}{29,896} & \multicolumn{2}{|c|}{27,095} & \multicolumn{2}{|c|}{2,801} \\
\hline Physical Health \& Well-Being & 6.84 & 2.19 & 8.85 & 1.42 & 9.04 & 1.24 & 7.48 & 1.87 \\
\hline Social Competence & 5.81 & 2.45 & 8.29 & 1.83 & 8.57 & 1.60 & 6.37 & 2.18 \\
\hline Emotional Maturity & 6.11 & 2.19 & 8.09 & 1.70 & 8.32 & 1.50 & 6.43 & 2.11 \\
\hline Language \& Cogn. Development & 6.40 & 2.82 & 8.62 & 1.74 & 8.86 & 1.46 & 6.83 & 2.41 \\
\hline Communication \& Gen. Knowledge & 4.18 & 3.20 & 7.85 & 2.53 & 8.24 & 2.23 & 5.19 & 2.85 \\
\hline \multicolumn{9}{|c|}{ Mexico } \\
\hline$N$ & \multicolumn{2}{|c|}{1,690} & \multicolumn{2}{|c|}{166,710} & \multicolumn{2}{|c|}{161,236} & \multicolumn{2}{|c|}{5,474} \\
\hline Physical Health \& Well-Being & 8.05 & 1.80 & 9.17 & 1.13 & 9.21 & 1.09 & 8.33 & 1.61 \\
\hline Social Competence & 6.81 & 2.34 & 8.56 & 1.56 & 8.62 & 1.20 & 6.90 & 2.10 \\
\hline Emotional Maturity & 6.62 & 2.06 & 8.16 & 1.57 & 8.23 & 1.52 & 6.50 & 1.93 \\
\hline Language \& Cogn. Development & 5.77 & 2.90 & 7.56 & 2.16 & 7.61 & 2.12 & 6.14 & 2.64 \\
\hline Communication \& Gen. Knowledge & 5.41 & 3.22 & 8.11 & 2.07 & 8.18 & 2.00 & 6.18 & 2.86 \\
\hline
\end{tabular}

Table 3

Effect Sizes of the Differences Between Mean EDI Scores Between Groups

\begin{tabular}{|c|c|c|c|}
\hline Domain & SN vs. Non-SN, All & $\begin{array}{l}\text { No SN, NFA vs. } \\
\text { No SN, No NFA }\end{array}$ & SN vs. No SN, NFA \\
\hline \multicolumn{4}{|c|}{ Canada } \\
\hline $\begin{array}{l}\text { Physical Health \& Well-Being } \\
\text { Social Competence } \\
\text { Emotional Maturity } \\
\text { Language \& Cogn. Development } \\
\text { Communication \& Gen. Knowledge }\end{array}$ & $\begin{array}{l}-1.50 \\
-1.64 \\
-1.41 \\
-1.57 \\
-1.50 \\
\end{array}$ & $\begin{array}{l}-1.22 \\
-1.58 \\
-1.39 \\
-1.59 \\
-1.28 \\
\end{array}$ & $\begin{array}{l}-0.48 \\
-0.37 \\
-0.30 \\
-0.31 \\
-0.45 \\
\end{array}$ \\
\hline \multicolumn{4}{|c|}{ Australia } \\
\hline $\begin{array}{l}\text { Physical Health \& Well-Being } \\
\text { Social Competence } \\
\text { Emotional Maturity } \\
\text { Language \& Cogn. Development } \\
\text { Communication \& Gen. Knowledge }\end{array}$ & $\begin{array}{l}-1.42 \\
-1.36 \\
-1.16 \\
-1.27 \\
-1.45 \\
\end{array}$ & $\begin{array}{l}-1.27 \\
-1.37 \\
-1.57 \\
-1.40 \\
-1.38 \\
\end{array}$ & $\begin{array}{l}-0.35 \\
-0.26 \\
-0.15 \\
-0.17 \\
-0.35 \\
\end{array}$ \\
\hline \multicolumn{4}{|c|}{ Mexico } \\
\hline $\begin{array}{l}\text { Physical Health \& Well-Being } \\
\text { Social Competence } \\
\text { Emotional Maturity } \\
\text { Language \& Cogn. Development } \\
\text { Communication \& Gen. Knowledge }\end{array}$ & $\begin{array}{l}-0.99 \\
-1.12 \\
-0.98 \\
-0.83 \\
-1.31\end{array}$ & $\begin{array}{l}-0.80 \\
-1.15 \\
-1.13 \\
-0.69 \\
-1.00\end{array}$ & $\begin{array}{c}-0.17 \\
-0.04 \\
0.06 \\
-0.14 \\
-0.27\end{array}$ \\
\hline
\end{tabular}


Table 4

Children Without Special Needs: Effect Sizes of Comparisons Between Those Who Have a Specific Special Impairment and Those Who Do Not

\begin{tabular}{|c|c|c|c|c|c|c|}
\hline Domain & $\begin{array}{l}\text { Physical } \\
\text { Disability }\end{array}$ & $\begin{array}{c}\text { Visual } \\
\text { Impairment }\end{array}$ & $\begin{array}{c}\text { Hearing } \\
\text { Impairment }\end{array}$ & $\begin{array}{c}\text { Speech } \\
\text { Impairment }\end{array}$ & $\begin{array}{l}\text { Learning } \\
\text { Disability }\end{array}$ & $\begin{array}{l}\text { Behaviour } \\
\text { Problem }\end{array}$ \\
\hline \multicolumn{7}{|c|}{ Canada } \\
\hline$N$ & $\begin{array}{l}\text { with/without } \\
668 / 164138\end{array}$ & $\begin{array}{c}\text { with/without } \\
856 / 37569\end{array}$ & $\begin{array}{c}\text { with/without } \\
605 / 37511\end{array}$ & $\begin{array}{l}\text { with/without } \\
4460 / 36251\end{array}$ & $\begin{array}{l}\text { with/without } \\
1149 / 37445\end{array}$ & $\begin{array}{l}\text { with/without } \\
1956 / 37119\end{array}$ \\
\hline Physical Health \& Well-Being & -1.03 & -0.12 & -0.03 & -0.42 & -0.86 & -0.46 \\
\hline Social Competence & -0.25 & -0.09 & -0.16 & -0.41 & -1.19 & -1.87 \\
\hline Emotional Maturity & -0.20 & -0.10 & -0.10 & -0.32 & -0.84 & -2.08 \\
\hline Language \& Cogn. Development & -0.24 & 0.01 & -0.06 & -0.68 & -1.76 & -0.56 \\
\hline Communication \& Gen. Knowl. & -0.23 & 0.03 & -0.30 & -1.13 & -1.14 & -0.31 \\
\hline \multicolumn{7}{|c|}{ Australia } \\
\hline$N$ & $\begin{array}{c}\text { with/without } \\
112 / 28037\end{array}$ & $\begin{array}{c}\text { with/without } \\
352 / 27355\end{array}$ & $\begin{array}{c}\text { with/without } \\
215 / 27412\end{array}$ & $\begin{array}{l}\text { with/without } \\
1483 / 26215\end{array}$ & $\begin{array}{c}\text { with/without } \\
292 / 27134\end{array}$ & $\begin{array}{c}\text { with/without } \\
401 / 27137\end{array}$ \\
\hline Physical Health \& Well-Being & -1.49 & -0.33 & -0.25 & -0.42 & -1.10 & -0.43 \\
\hline Social Competence & -0.37 & -0.10 & -0.30 & -0.29 & -1.20 & -1.76 \\
\hline Emotional Maturity & -0.25 & -0.08 & -0.30 & -0.20 & -0.79 & -2.03 \\
\hline Language \& Cogn. Development & -0.27 & -0.02 & -0.09 & -0.47 & -1.50 & -0.53 \\
\hline Communication \& Gen. Knowl. & -0.17 & -0.05 & -0.31 & -1.05 & -1.43 & -0.39 \\
\hline \multicolumn{7}{|c|}{ Mexico } \\
\hline$N$ & $\begin{array}{l}\text { with/without } \\
459 / 171031 \\
\end{array}$ & $\begin{array}{l}\text { with/without } \\
647 / 168825\end{array}$ & $\begin{array}{l}\text { with/without } \\
226 / 169260\end{array}$ & with/without & with/without & $\begin{array}{c}\text { with/without } \\
2694 / 166514\end{array}$ \\
\hline Physical Health \& Well-Being & -1.49 & -0.19 & -0.46 & & & -0.52 \\
\hline Social Competence & -0.63 & -0.01 & -0.53 & & & -1.29 \\
\hline Emotional Maturity & -0.47 & -0.24 & -0.57 & & & -1.48 \\
\hline Language \& Cogn. Development & -0.71 & 0.07 & -0.37 & & & -0.43 \\
\hline Communication \& Gen. Knowl. & -0.87 & -0.01 & -1.08 & & & -0.72 \\
\hline
\end{tabular}

General Knowledge, where it reached a borderline magnitude of -0.30 . In Australia, the borderline small/moderate magnitude was also reached for Social Competence and Emotional Maturity domains. However, in Mexico, children with hearing impairments scored consistently lower than those without, reaching moderate effect sizes on all domains with the exception of Communication Skills and General Knowledge, where the effect size was large.

Speech impairment and learning disability showed remarkably similar patterns for this population in Canada and Australia. Speech impairment was associated with small or moderate differences in all domains except Communication Skills and General Knowledge, where the effect size was large. Learning disability was associated with large or borderline large $(-0.79)$ effect sizes in all five domains. The most consistent pattern emerged for behaviour problems: in all three countries, the difference between children with this particular problem and those without was large in Social Competence and Emotional Maturity (effect sizes -1.29 to -2.08), and moderate for the remaining three domains (effect sizes -0.31 to -0.72 ).

Children with Special Needs. Perhaps the most informative and revealing results were demonstrated by the comparison of children with and without a specific impairment among children with Special Needs (see Table 5). In all three countries, children with physical impairment were rated lower than those without in the Physical Health domain, with effect sizes 
borderline large (-0.78 in Canada and -0.80 in Australia) to large (-1.02 in Mexico). Otherwise, however, with few exceptions, children with physical, visual, and hearing impairments were rated higher than those without these particular problems, with effect sizes in moderate ranges (though the results for Australia have to be interpreted with caution due to small sample sizes).

Table 5

Children with Special Needs: Effect Sizes of Comparisons Between Those Who Have a Specific Special Impairment and Those Who Do Not

\begin{tabular}{|c|c|c|c|c|c|c|}
\hline Domain & $\begin{array}{l}\text { Physical } \\
\text { Disability }\end{array}$ & $\begin{array}{c}\text { Visual } \\
\text { Impairment }\end{array}$ & $\begin{array}{c}\text { Hearing } \\
\text { Impairment }\end{array}$ & $\begin{array}{l}\text { Speech } \\
\text { Impairment }\end{array}$ & $\begin{array}{l}\text { Learning } \\
\text { Disability }\end{array}$ & $\begin{array}{l}\text { Behaviour } \\
\text { Problem }\end{array}$ \\
\hline \multicolumn{7}{|c|}{ Canada } \\
\hline$N$ & $\begin{array}{c}\text { with/without } \\
219 / 3214\end{array}$ & $\begin{array}{c}\text { with/without } \\
66 / 753\end{array}$ & $\begin{array}{c}\text { with/without } \\
151 / 728\end{array}$ & $\begin{array}{c}\text { with/without } \\
749 / 636\end{array}$ & $\begin{array}{c}\text { with/without } \\
369 / 703\end{array}$ & $\begin{array}{c}\text { with/without } \\
309 / 698\end{array}$ \\
\hline Physical Health \& Well-Being & -0.78 & 0.15 & 0.69 & 0.38 & -0.25 & 0.23 \\
\hline Social Competence & 0.54 & 0.40 & 0.55 & 0.40 & -0.52 & -0.74 \\
\hline Emotional Maturity & 0.56 & 0.27 & 0.54 & 0.38 & -0.35 & -1.24 \\
\hline Language \& Cogn. Dev. & 0.40 & 0.14 & 0.46 & -0.05 & -0.91 & 0.07 \\
\hline Communication \& Gen. Knowl. & 0.65 & 0.68 & 0.21 & -0.31 & -0.55 & 0.46 \\
\hline \multicolumn{7}{|c|}{ Australia } \\
\hline$N$ & $\begin{array}{c}\text { with/without } \\
35 / 604\end{array}$ & $\begin{array}{c}\text { with/without } \\
12 / 590\end{array}$ & $\begin{array}{c}\text { with/without } \\
10 / 592\end{array}$ & $\begin{array}{c}\text { with/without } \\
112 / 491\end{array}$ & $\begin{array}{c}\text { with/without } \\
123 / 450\end{array}$ & $\begin{array}{c}\text { with/without } \\
32 / 565\end{array}$ \\
\hline Physical Health \& Well-Being & -0.80 & 0.09 & -0.28 & 0.09 & -0.47 & -0.33 \\
\hline Social Competence & 0.44 & 0.24 & -0.24 & 0.07 & -0.73 & -1.13 \\
\hline Emotional Maturity & 0.49 & 0.06 & -0.42 & 0.14 & -0.42 & -1.40 \\
\hline Language \& Cogn. Dev. & 0.30 & 0.39 & 0.25 & 0.02 & -0.92 & -0.45 \\
\hline Communication \& Gen. Knowl. & 0.55 & 0.45 & -0.28 & -0.59 & -0.65 & -0.02 \\
\hline \multicolumn{7}{|c|}{ Mexico } \\
\hline$N$ & $\begin{array}{c}\text { with/without } \\
119 / 1381\end{array}$ & $\begin{array}{c}\text { with/without } \\
51 / 1391\end{array}$ & $\begin{array}{c}\text { with/without } \\
55 / 1400\end{array}$ & with/without & with/without & $\begin{array}{c}\text { with/without } \\
189 / 1253\end{array}$ \\
\hline Physical Health \& Well-Being & -1.02 & -0.02 & 0.26 & & & 0.00 \\
\hline Social Competence & 0.10 & 0.32 & 0.27 & & & -0.80 \\
\hline Emotional Maturity & 0.18 & 0.42 & 0.30 & & & -1.11 \\
\hline Language \& Cogn. Dev. & -0.21 & 0.27 & 0.07 & & & -0.16 \\
\hline Communication \& Gen. Knowl. & 0.00 & 0.40 & -0.43 & & & -0.17 \\
\hline
\end{tabular}

Children with speech impairment had lower outcomes than children without only in the Communication Skills and General Knowledge domain (effect sizes moderate, -0.31 in Canada and -0.59 in Australia), but in Canada, they were rated higher than other children in all but the Language and Cognitive Development domain (moderate effect sizes), while in Australia the effect sizes were very small indicating no difference. In both Canada and Australia, children with learning disabilities had lower outcomes in all five domains on the EDI, with moderate to large effect sizes. Finally, behaviour problems indicated an area of less consistency among countries. In all three countries, children with specific behaviour problems had lower outcomes than other children in Social Competence and Emotional Maturity (effect sizes moderate to large); however, in Canada these children were actually rated higher than others in the Communication Skills and General Knowledge domain. In Australia, they were rated lower in Physical Health and Well-being and Language and Cognitive Development, with no difference in the Communication domain, while in Mexico, no other domains reached effect sizes indicative of a meaningful difference.

Children who Need Further Assessment. Children rated by teachers as NFA had consistently lower scores than their non-SN counterparts who were not NFA (Table 2). In comparison with children with SN, children in the NFA group had consistently higher scores in 
all five EDI domains in Canada (with effect sizes in the moderate range; Table 3). In Australia, NFA children had higher scores than children with SN, but the differences reached the meaningful level only in Physical Health and Well-being, and Communication Skills and General Knowledge domains. In Mexico, only the difference in the Communication Skills and General Knowledge domain had a borderline moderate effect size (-0.27).

When the subgroup of NFA children with one impairment was investigated in more detail, it became clear that children with suspected learning disability were the ones at risk for low school readiness in most areas, followed by children with behaviour problems being at large risk in Social Competence and Emotional Maturity domains (see Table 6). As in the other subgroups, however, children with visual, hearing, and speech impairments generally were rated higher than others in the school readiness domains not directly affected by their problem.

\section{Discussion}

The analyses in this paper confirm that children with Special Needs identified prior to school entry do indeed struggle in school in comparison with their typically-developing peers. The comparisons of specific areas of impairment elucidate to some extent the impact of those impairments on school readiness domains. The results also show that children without identified Special Needs, yet with some impairments, are vulnerable too, in particular those with learning disability, speech impairment, or behaviour issues. Moreover, children judged as Needing Further Assessment appear to struggle in kindergarten; perhaps not as much as children with identified Special Needs, but with the same pattern in relation to specific impairments. Finally, despite some differences in the special education environment in the three countries studied here, the patterns are remarkably similar among Canada, Australia, and Mexico. 
Table 6

Children Who Need Further Assessment: Effect Sizes of Comparisons Between Those Who Have a Specific Special Impairment and Those Who Do Not

\begin{tabular}{|c|c|c|c|c|c|c|}
\hline Domain & $\begin{array}{l}\text { Physical } \\
\text { Disability }\end{array}$ & $\begin{array}{c}\text { Visual } \\
\text { Impairment }\end{array}$ & $\begin{array}{c}\text { Hearing } \\
\text { Impairment }\end{array}$ & $\begin{array}{c}\text { Speech } \\
\text { Impairment }\end{array}$ & $\begin{array}{l}\text { Learning } \\
\text { Disability }\end{array}$ & $\begin{array}{l}\text { Behaviour } \\
\text { Problem }\end{array}$ \\
\hline \multicolumn{7}{|c|}{ Canada } \\
\hline$N$ & $\begin{array}{c}\text { with/without } \\
81 / 13153\end{array}$ & $\begin{array}{c}\text { with/without } \\
105 / 3076\end{array}$ & $\begin{array}{c}\text { with/without } \\
123 / 3051\end{array}$ & $\begin{array}{l}\text { with/without } \\
2082 / 2400\end{array}$ & $\begin{array}{c}\text { with/without } \\
537 / 2967\end{array}$ & $\begin{array}{c}\text { with/without } \\
896 / 2837\end{array}$ \\
\hline Physical Health \& Well-Being & -0.64 & -0.20 & 0.28 & 0.24 & -0.03 & 0.22 \\
\hline Social Competence & 0.38 & 0.03 & 0.31 & 0.46 & -0.31 & -0.96 \\
\hline Emotional Maturity & 0.23 & 0.06 & 0.37 & 0.50 & 0.06 & -1.26 \\
\hline Language \& Cogn. Development & 0.18 & 0.00 & 0.29 & 0.15 & -0.75 & 0.25 \\
\hline Communication \& Gen. Knowledge & 0.32 & 0.18 & 0.25 & -0.49 & -0.27 & 0.49 \\
\hline \multicolumn{7}{|c|}{ Australia } \\
\hline$N$ & $\begin{array}{c}\text { with/without } \\
15 / 1821\end{array}$ & $\begin{array}{c}\text { with/without } \\
34 / 1726\end{array}$ & $\begin{array}{c}\text { with/without } \\
44 / 1694\end{array}$ & $\begin{array}{c}\text { with/without } \\
390 / 1357\end{array}$ & $\begin{array}{c}\text { with/without } \\
81 / 1529\end{array}$ & $\begin{array}{c}\text { with/without } \\
80 / 1656\end{array}$ \\
\hline Physical Health \& Well-Being & -0.79 & 0.19 & 0.02 & 0.14 & -0.22 & 0.13 \\
\hline Social Competence & 0.02 & 0.43 & 0.17 & 0.41 & -0.25 & -1.01 \\
\hline Emotional Maturity & 0.02 & 0.32 & 0.12 & 0.45 & 0.03 & -1.41 \\
\hline Language \& Cogn. Development & 0.13 & 0.35 & 0.28 & 0.17 & -0.54 & 0.15 \\
\hline Communication \& Gen. Knowledge & 0.43 & 0.64 & 0.24 & -0.32 & -0.33 & 0.38 \\
\hline \multicolumn{7}{|c|}{ Mexico } \\
\hline$N$ & $\begin{array}{c}\text { with/without } \\
121 / 4477\end{array}$ & $\begin{array}{c}\text { with/without } \\
74 / 4465\end{array}$ & $\begin{array}{c}\text { with/without } \\
90 / 4445\end{array}$ & with/without & with/without & $\begin{array}{c}\text { with/without } \\
864 / 3641\end{array}$ \\
\hline Physical Health \& Well-Being & -1.00 & 0.08 & 0.00 & & & 0.11 \\
\hline Social Competence & -0.05 & 0.46 & 0.11 & & & -0.56 \\
\hline Emotional Maturity & 0.30 & 0.57 & -0.05 & & & -0.82 \\
\hline Language \& Cogn. Development & -0.46 & 0.23 & 0.19 & & & 0.08 \\
\hline Communication \& Gen. Knowledge & -0.42 & 0.26 & -0.28 & & & 0.00 \\
\hline
\end{tabular}

Note. A minus sign indicates that the mean score for children with the impairment was lower than that for children without the impairment.

The percentages of boys who have special needs, as well as boys who need further assessment are strikingly higher than the corresponding percentages of girls in all three countries. The unequal distribution of special needs status between boys and girls is not surprising. Boys have more biological health problems than girls and are more likely to have developmental delays, intellectual disabilities, and behavioural disorders (Gissler, Järvelin, Louhiala, \& Hemminki, 1999). Consequently, they make up the majority of the children in special educational programs. According to the 2006 Statistics Canada Participation and Activity Limitation Survey (Statistics Canada, 2008), the percentage of 5- to 9-year-old Canadian children with disabilities is $4.2 \%$, representing some 74,580 individuals. The gender breakdown for this age group is $5.3 \%$ boys and $3.0 \%$ girls, which is virtually identical to the one observed in our Canadian sample.

The comparable data for Australia indicate that $8.3 \%$ of children $(10 \%$ boys and $6.5 \%$ girls) have disabilities; however, these results are reported for children 0-14 (Australian Institute of Health and Welfare, 2006), which could account for the higher proportions than those reported in this paper for children age 5-6 years only. The ratio of boys to girls, however, remains similar in all reports.

Exploration of population statistics for Mexico indicates that the rates of reported disabilities are considerably lower than in Canada and Australia: approximately 1\% (Instituto Nacional De Estadistica Geografia e Informatica, 2000), with about 0.7\% girls and 1.0\% boys age 6-14 years having a disability. However, these numbers come from the author's combination of two separate tables (one for reported disabilities and one for population totals), and therefore may be subject to some error. Nevertheless, these proportions are reflected in this study of kindergarten children, with only $1 \%$ reported as having special needs. 
The detailed comparisons of the associations between children's specific impairment and the school readiness outcomes allow for more nuanced understanding of the difficulties young children face in their transition to school. This type of analysis can help focus the attention of intervention and transition practices away from particular diagnosis. The World Health Organization (2007) promotes the functional approach through application of the International Classification of Functioning, Disability and Health for Children and Youth, which provides a common language for a multidisciplinary approach to treatment and intervention. In transitioning from one setting to another (like preschool to school), with discontinuity of services due to system changes, assessments frequently need to be repeated and children re-tested; this leads to valuable time wasted which could otherwise be available for intervention during these years of early development (Fowler et al., 1991). The evidence in this study showed that learning issues have the strongest overall impact on children's school readiness, both among children with and without special needs, and consistently among the three countries. In contrast, students with visual and hearing impairments, while experiencing some difficulty, did not fare as poorly as those children having other types of problems. In fact, among children at risk-those with special needs and those with NFA - children with visual and hearing impairments had better outcomes on the EDI domains than children with other impairments. Children with a physical disability tended to have lower scores than others only in the area directly relevant to their problem: Physical Health and Well-being. Outcomes for children with speech impairments (available only for Canada and Australia) were also consistent among those at risk (SN and NFA): these children were rated lower than others in the Communication Skills and General Knowledge domain and tended to be rated higher in the remaining ones. For children without $\mathrm{SN}$, having a physical or speech impairment appeared to affect all developmental areas negatively, although not to the same extent as the one directly related to their health problem. Clearly, therefore, for some areas of impairment, progress can be made by targeting single domains of school readiness to improve children's functioning. Other special needs areas have a broader impact on children's outcomes and require overall transition and intervention strategies.

Most of the results reported here are remarkably consistent among the three countries. The degree of similarity in the patterns was greater for Canada and Australia than for either of these two countries with Mexico. For example, in contrast to the Canadian and Australian samples, children with physical and sensory impairments in the Mexican sample appeared to be affected in more than just one area. Perhaps this may be explained by the fact that there are only five broad categories in the special education policies in Mexico (Mount-Cors, 2007), and thus it is likely that children with physical disability may be suffering from other, not described problems affecting their outcomes. Moreover, there appears to be a streaming of intervention into transitory services delivered at school (children with learning, behavioural, and speech problems), lasting for no more than 18 months, and permanent, delivered in dedicated centres, in case of disabilities with severity and chronicity to warrant long-term support (physical, sensory, intellectual, and neurological disabilities; Rhodes, 2000). A reported 5.6\% of children eligible for these services actually receive them.

The difference between the groups of children with SN and those with NFA could be conceptualized as one between children whose special educational needs had been identified prior to school entry, and those whose special needs are beginning to exert impact on their school life. Not surprisingly, children with SN did have poorer outcomes than children with NFA, but the differences did not reach large magnitude and were not entirely consistent among the countries: in Canada, children with NFA did better than children with SN in all areas, in 
Australia the differences were only meaningful in two domains, and in Mexico, although the scores of children with SN were lower, they were not meaningfully so. Like children with SN, children with NFA had consistently lower outcomes in all EDI domains than the non-SN, nonNFA group. This is also not surprising as their lower abilities were likely what alerted the teachers to report on their need for further assessment. In contrast to children with SN, the NFA group would likely not be eligible for any special education support. It appears that more effort should be directed into the pre-school identification process, as identification of the needs status (not necessarily a diagnosis), though not a perfect solution by any means, at least gives the child greater chances to receive educational supports (Janus et al., 2008).

The context of the classroom, as well as of the transition process, including the availability of special accommodations and educational assistants, can impact children's outcomes (Janus et al., 2008). Lack of contextual data in this investigation is a limitation that should be addressed in future research. While the SN classification was based on a designation by the appropriate school authority in each of the samples, the NFA group was based on teacher perception, which could vary considerably among teachers, as well as among jurisdictions and countries, and could have influenced the results.

There are also limitations in what impairments can predict. In longitudinal studies using child adjustment measures based on teacher ratings, disability impairment was less predictive than social skills and self-regulation at 3 years of age (McIntyre, Blacher, \& Baker, 2006) or children's personality (Reed-Victor, 2004). The main limitation of the current study is the lack of data on transition practices or intervention accompanying children with diagnosed and suspected special needs. Therefore, there is still need for clear evidence to determine whether the approach suggested above, related to the type of impairments, would actually make a difference in children's adjustment to school. Future research in this area needs to include evidence on existence and effectiveness of transition practices for children with special needs.

The data in this study present only one, though meaningful, side of the complex process of transition - the connection between children's functional impairment and their success at school. This type of evidence can be useful in the board-level planning and policies regarding accommodations and programming for children who enter school with impairment. As stated above, more detailed and individualized evidence is needed to address parent and child perspectives in transition.

In conclusion, the EDI is capturing outcomes of a particular transition year between preschool and school. Despite a great variation among special education policies and definitions within and between jurisdictions in the three countries studied, the analyses of the data on children's developmental outcomes in relation to their impairments showed a number of remarkable similarities. Our study is unique in contributing international data on school readiness among children with special needs to the discourse on successful transition to school for these children. The similarities among countries indicate that there are universalities in child development, which need to be explored and acted upon to facilitate the process of transition for all children.

\section{References}

Andrich, D., \& Styles, I. (2004). Final report on the psychometric analysis of the Early Development Instrument (EDI) using the Rasch Model: A technical paper commissioned for the development of the Australian Early Development Index (AEDI). Perth: Murdoch University.

Aussie Educator. (n.d.). Special education: States \& territories. Retrieved from http://www.aussieeducator.org 
.au/education/specificareas/specialeducation/specialeducation.html

Australian Capital Territory. (2004). Interim ACT student disability criteria 2004. Retrieved from http://www .det.act.gov.au/_data/assets/pdf_file/0009/17829/DisabilityCriteriaInterim2004.pdf

AEDI Partnership. (2007). Australian Early Development Index: Building better communities for children. Australian results 2004-2006. Retrieved from http://video.wch.org.au/aedi /AustralianCommunitiesApril07.pdf

Australian Institute of Health and Welfare. (2006). Disability updates: Children with disabilities. Bulletin No. 42. AIHW cat. no. AUS 19. Canberra: Author.

Brinkman, S., Silburn, S., Lawrence, D., Goldfeld, S., Sayers, M., \& Oberklaid, F. (2007). Investigating the validity of the Australian Early Development Index. Early Education and Development, 18(3), 427452. doi:10.1080/10409280701610812

Conn-Powers, M. C., Ross-Allen, J., \& Holborn, S. (1990). Transition of young children into the elementary education mainstream. Topics in Early Childhood Special Education, 9(4), 91-105. doi:10.1177 /027112149000900409

Dempsey, I., Foreman, P., \& Jenkinson, J. (2002). Educational enrolment of students with a disability in New South Wales and Victoria. International Journal of Disability, Development and Education, 49(1), 31-46. doi:10.1080/10349120120115316

Duncan, N. (2003). Awkward customers? Parents and provision for special educational needs. Disability and Society, 18(3), 341-356. doi:10.1080/0968759032000052905

Early, D. (2004). Services and programs that influence young children's school transitions. In R. E. Tremblay, R. Barr, \& R. Peters (Eds.), Encyclopedia on early childhood development (online). Montreal, QC: Centre of Excellence for Early Childhood Development (pp. 1-5). Retrieved from http://www .excellence-earlychildhood.ca/documents/EarlyANG.pdf.

Early, D. M., Pianta, R. C., Taylor, L. C., \& Cox, M. J. (2001). Transition practices: Findings from a national survey of kindergarten teachers. Early Childhood Education Journal, 28(3), 199-206. doi:10.1023 /A:1026503520593

Entwisle, D. R., \& Alexander, K. L. (1999). Early schooling and social stratification. In R. C. Pianta \& M. J. Cox (Eds.), The transition to kindergarten (pp. 13-18). Baltimore, MD: Paul H. Brookes.

Forget-Dubois, N., Lemelin, J., Boivin, M., Dionne, G., Séguin, J. R., Vitaro, F., \& Tremblay, R. E. (2007). Predicting early school achievement with the EDI: A longitudinal population-based study. Early Education and Development, 18(3), 405-426. doi:10.1080/10409280701610796

Fowler, S. A., Schwartz, I., \& Atwater, J. (1991). Perspectives on the transition from preschool to kindergarten for children with disabilities and their families. Exceptional Children, 58(2), 136-145.

Gissler, M., Järvelin, M-R., Louhiala, P., \& Hemminki, E. (2007). Boys have more health problems in childhood than girls: Follow-up of the 1987 Finnish birth cohort. Acta Paediatrica, 88(3), 310-314. doi:10 .1080/08035259950170088

Guhn, M., Gadermann, A., \& Zumbo, B. D. (2007). Does the EDI measure school readiness in the same way across different groups of children? Early Education and Development, 18(3), 453-472. doi:10.1080 $/ 10409280701610838$

Guhn, M., \& Goelman, H. (2011). Bioecological theory, early child development and the validation of the population-level Early Development Instrument. Social Indicators Research, 103(2), 193-217. doi:10 .1007/s11205-011-9842-5

Healthy Child Manitoba. (2002). Guideline for early childhood transition to school for children with special needs. Winnipeg, MB. Available from http://www.gov.mb.ca/healthychild/publications /protocol_cwsn.pdf

Husted, J. A., Cook, R. J., Farewell, V. T., \& Gladman, D. D. (2000). Methods for assessing responsiveness: A critical review and recommendations. Journal of Clinical Epidemiology, 53(5), 459-468. doi:10.1016 /S0895-4356(99)00206-1

Instituto Nacional De Estadistica Geografia e Informatica. (2000). XII Censo General de Población y Vivienda 2000. Retrieved from http://www.inegi.org.mx/sistemas/sisept/default.aspx?t=mdis10\&s=est\&c=8304

Janus, M. (2004) Voices from the field-Transition to school practices: The need for evidence. In R. E. Tremblay, R. Barr, \& R. Peters (Eds.), Encyclopedia on early childhood development. Montreal, QC: Centre of Excellence for Early Childhood Development (pp.1-7). Retrieved from http://www 
.excellence-earlychildhood.ca/documents/JanusANG.pdf.

Janus, M. (2011). Transition to school: Child, family, and community-level determinants. In D. M. Laverick \& M. R. Jalongo (Eds.), Transitions to early care and education: International perspectives on making schools ready for young children (pp. 177-187). Dordrecht, The Netherlands: Springer.

Janus, M., Brinkman, S. A., \& Duku, E. K. (2011). Validity and psychometric properties of the Early Development Instrument in Canada, Australia, United States, and Jamaica. Social Indicators Research, 103(2), 283-297. doi:10.1007/s11205-011-9846-1

Janus, M., \& Duku, E. (2007). The school entry gap: Socioeconomic, family, and health factors associated with children's school readiness to learn. Early Education and Development, 18(3), 375-404. doi:10 $.1080 / 10409280701610796 \mathrm{a}$

Janus, M., \& Duku, E. (2008). Gold Standard Normative II data. School Readiness to Learn (SRL) Project: Results. Hamilton, ON: McMaster University. Retrieved from http://www.offordcentre.com/readiness /files/Reports 2008_05_27_Gold_Data.pdf

Janus, M., Duku, E., \& Hughes, D. (2010). Patterns of school readiness among selected groups of Canadian children: Children with special needs and children with diverse language backgrounds. Canadian Council for Learning. Retrieved from http://www.ccl-cca.ca/pdfs/OtherReports/Janus-FinalReport .pdf.

Janus, M., Kopechanski, L., Cameron, R., \& Hughes, D. (2008). In transition: Experiences of parents of children with special needs at school entry. Early Childhood Education Journal, 35(5), 479-485. doi:10 .1007/s10643-007-0217-0

Janus, M., Lefort, J., Cameron R., \& Kopechanski, L. (2007). Starting kindergarten: Transition issues for children with special needs. Canadian Journal of Education, 30(3), 628-648. doi:10.2307/20466656

Janus, M., \& Offord, D. R. (2007). Development and psychometric properties of the Early Development Instrument (EDI): A measure of children's school readiness. Canadian Journal of Behavioural Science, 39(1), 1-22. doi:10.1037/cjbs2007001

Jimerson, S., Egeland, B., \& Teo, A. (1999). A longitudinal study of achievement trajectories: Factors associated with change. Journal of Educational Psychology, 91(1), 116-126. doi:10.1037//00220663.91 .1 .116

Lloyd, J. E. V., Irwin, L. G., \& Hertzman, C. (2009). Kindergarten school readiness and fourth-grade literacy and numeracy outcomes of children with special needs: A population-based study. Educational Psychology, 29(5), 583-602. doi:10.1080/01443410903165391

LoCasale-Crouch, J., Mashburn, A., Downer, J., \& Pianta, R. (2008). Pre-kindergarten teachers' use of transition practices and children's adjustment in kindergarten. Early Childhood Research Quarterly, 23(1), 124-139. doi:10.1016/j.ecresq.2007.06.001

McIntyre, L. L., Blacher, J., \& Baker, B. L. (2006). The transition to school: Adaptation in young children with and without intellectual disability. Journal of Intellectual Disability Research, 50(5), 349-361. doi:10.1111/j.1365-2788.2006.00783.x

McIntyre, L. L., \& Wildenger, L. K. (2011). Examining the state of the science: Empirical support for kindergarten transition practices for students with disabilities. In D. M. Laverick \& M. R. Jalongo (Eds.), Transitions to early care and education: International perspectives on making schools ready for young children (pp. 29-42). Dordrecht, The Netherlands: Springer.

Meisels, S. J. (1999). Assessing readiness. In R. C. Pianta \& M. J. Cox (Eds.), The transition to kindergarten (pp. 39-66). Baltimore, MD: Paul H. Brookes.

Mount-Cors, M. F. (2007). Special education in Mexico. Learn NC Editions, 3.3. Retrieved from http://www .learnnc.org/lp/editions/brdglangbarriers/1911

Mulvihill, B. A., Shearer, D., \& Lee Van Horn, M. (2002). Training, experience, and child care providers' perceptions of inclusion. Early Childhood Research Quarterly, 17(2), 197-215. doi:10.1016/S08852006(02)00145-X

Pianta, R. C., \& Kraft-Sayre, M. (2003). Successful kindergarten transition: Your guide to connecting children, families, and schools. Baltimore, MD: Paul H. Brookes.

Ramey, C., \& Ramey, S. (2004). Early learning and school readiness: Can early intervention make a difference? Merrill-Palmer Quarterly, 50(4), 471-491. doi:10.1353/mpq.2004.0034 
Reed-Victor, E. (2004). Individual differences and early school adjustment: Teacher appraisals of young children with special needs. Early Child Development \& Care, 174(1), 59-79. doi:10.1080 $/ 0300443032000153499$

Rhodes, R. (2000). School psychology and special education in Mexico: An introduction for practitioners. School Psychology International, 21(3), 252-264. doi:10.1177/0143034300213003

Rous, B., Hemmeter, M. L., \& Schuster, J. W. (1994). Sequenced transition to education in the public schools: A systems approach to transition planning. Topics in Early Childhood Special Education, 14(3), 374393. doi:10.1177/027112149401400307

Santibañez, L., Vernez, G., \& Razquin, P. (2005). Education in Mexico: Challenges and opportunities. Santa Monica, CA: RAND Corporation.

Statistics Canada. (2008). Participation and Limitations Survey: 2006 Census. (Rep. No. 89-628-XWE). Retrieved from http://www.statcan.gc.ca/bsolc/olc-cel/olc-cel?catno=89-628-X\&lang=eng

Valeo, A. (2003). Special education tribunals in Ontario. International Journal of Special Education, 18(2), 18-30. Retrieved from http://www.internationaljournalofspecialeducation.com

Victoria Department of Education and Early Childhood Development. (n.d.). Sharing our journey protocol. Retrieved from http://www.eduweb.vic.gov.au/edulibrary/public/earlychildhood/healthwellbeing /sharingourjourneyprotocol.pdf

Wolery, M. (1999). Children with disabilities in early elementary school. In R. C. Pianta \& M. J. Cox (Eds.), The transition to kindergarten (pp. 253-280). Baltimore, MD: Paul H. Brookes.

World Health Organization. (2007). International Classification of Functioning, Disability and Health: Child and youth version. Geneva: Author.

Zuckerman, B., \& Halfon, N. (2003). School readiness: An idea whose time has arrived. Pediatrics, 111(6), 1433-1436. doi:10.1542/peds.111.6.1433

\section{Author's Note}

Correspondence concerning this article should be addressed to Magdalena Janus, Offord Centre for Child Studies, McMaster University, Chedoke Patterson Building 218, 1280 Main St West, Hamilton, ON L8S 4K1. E-mail: janusm@mcmaster.ca 